\title{
Where do biospheric values come from? A connectedness to nature perspective
}

\author{
Christian Martin a, *, Sandor Czellar ${ }^{\mathrm{b}}$ \\ ${ }^{a}$ National University of Ireland Maynooth, School of Business, Rye Hall Extension, Maynooth, Co. Kildare, Ireland \\ ${ }^{\mathrm{b}}$ University of Lausanne, Quartier UNIL-Dorigny, Bâtiment Anthropole, 1015 Lausanne, Switzerland
}

\section{A R T I C L E I N F O}

\section{Article history:}

Received 13 October 2016

Received in revised form

16 April 2017

Accepted 19 April 2017

Available online 23 April 2017

\section{Keywords:}

Biospheric values

Environmental values

Self-nature connection

Environmental identity

Sustainable behavior

\begin{abstract}
A B S T R A C T
While extant research suggests that holding biospheric values may foster environmentally friendly behavior, we need to learn more about the development of such values at an individual level. Our conceptual framework proposes that individual environmental identity could play a role in the formation of a biospheric value orientation. We conducted two cross-sectional surveys $(\mathrm{N}=494, \mathrm{~N}=107)$ and a quasi-experimental study $(\mathrm{N}=271)$ in the US and Europe and with demographically different samples to investigate this conceptual linkage. Our findings show that stronger (vs. weaker) self-nature connections in individuals are related to stronger (vs. weaker) biospheric value orientations, which in turn are associated with various forms of sustainable behavior. Our research links two major literature streams in environmental psychology (i.e., research on self-nature connections and biospheric values) by proposing a developmental account of the relations between environmental identity and relevant values.
\end{abstract}

(๑) 2017 Elsevier Ltd. All rights reserved.

\section{Introduction}

According to the United Nations Millennium Declaration, insufficient respect for nature is one of the greatest issues facing the sustainable development of our planet (United Nations General Assembly, 2000). Despite current efforts, substantial additional endeavors need to be undertaken to actively promote ecological consumption practices on a worldwide scale (National Geographic, 2014). For example, Dietz, Gardner, Gilligan, Stern, and Vandenbergh (2009) estimated that the emission of 123 million metric tons of carbon (i.e., 20\% of the emissions caused by households) could be prevented in the US every year if households used already available technologies and adopted more effective behaviors. This estimate reflects a lack of motivation to behave and learn how to behave in an environmentally friendly way, as this reduction could be achieved without households experiencing noticeable inconveniences.

In light of these pressing challenges, there is a need to better understand the factors that contribute to sustainable consumption practices. Researchers have already devoted considerable attention to the factors that may facilitate environmentally friendly behaviors

\footnotetext{
* Corresponding author.

E-mail addresses: Christian.Martin@nuim.ie (C. Martin), Sandor.Czellar@unil.ch (S. Czellar).
}

(e.g., Gifford \& Nilsson, 2014; Osbaldiston \& Schott, 2012; Schultz \& Kaiser, 2012). An important such factor is the concept of biospheric values, which is defined as a value orientation in which "people judge phenomena on the basis of costs or benefits to ecosystems or the biosphere" (Stern \& Dietz, 1994, p. 70). Values are transsituational beliefs that can guide individual decisions across a variety of contexts and domains (Schwartz, 2012). The Theory of Basic Values identifies a system of ten fundamental, cross-culturally relevant value orientations that seem to motivate human actions around the globe (Schwartz, 2012). Differences in values between individuals can emerge through exposure to different environmental conditions, social learning, and evolutionary processes (Heine \& Norenzayan, 2006). However, the developmental factors that strengthen a certain value orientation seem to differ between value orientations. For example, values reflecting selftranscendence (vs. self-enhancement) in the Schwartz Theory of Basic Values may grow stronger when people start families. This is because starting a family may induce a stronger concern for the well-being of others and a decrease in the concern for ones' own achievements (Schwartz, 2007). While this explanation may hold true for self-transcendental values, different types of insecurities, for example, have been related to the formation of materialistic values (Kasser, Ryan, Couchman, \& Sheldon, 2004).

From the perspective of the Schwartz value system, biospheric values are part of the Universalism value orientation, this latter 
being characterized by a concern "for the welfare of those in larger society and world and for nature" (Schwartz, 2012, p. 7; see also Steg \& de Groot, 2012). Given the relevance of biospheric values in influencing pro-environmental behavior (Steg \& de Groot, 2012; Steg, Bolderdijk, Keizer, \& Perlaviciute, 2014), social marketers and public policy makers should be interested in cultivating a biospheric value orientation in individual citizens. To do so, it is important to understand how biospheric values develop. However, our knowledge about the individual-level formation of biospheric values is limited and we need further insights into factors that may strengthen this value orientation in individuals (Steg \& de Groot, 2012).

We respond to this research call by identifying an individual's sense of connection to the natural environment as a potentially important factor that may facilitate the development of biospheric values. The findings of our three studies suggest that feeling connected to nature is related to the formation of biospheric values, which in turn may be conducive to sustainable actions. Our research establishes conceptual and empirical links between the literature streams on biospheric values and environmental identity. Our findings have implications for social marketers and policy makers who wish to foster green behaviors. In particular, enabling and encouraging individuals to (re)connect with nature might help them nurture biospheric values, and eventually motivate them to behave more sustainably.

\subsection{Biospheric values}

Research on environmental value orientations has a long tradition. Stern and colleagues (Stern \& Dietz, 1994; Stern, Dietz, \& Kalof, 1993) proposed that three different value orientations (i.e., egoistic, altruistic, and biospheric) are relevant for shaping (un) sustainable behavior. An egoistic value orientation places personal gain at the center of individual decision making. Individuals holding an altruistic value orientation are concerned with the wellbeing of other humans (e.g., humanity in general, a certain nation, community, or a social group). People holding a biospheric value orientation tend to view their own and others' actions in light of the advantages and drawbacks for nature. Based on these conceptual foundations, an important research stream has developed around the role of biospheric values in environmental psychology (Steg \& de Groot, 2012). While the concept of biospheric values is the most prominent environmental values concept in the literature, other similar concepts (e.g., environmentalism, Steenkamp \& de Jong, 2010; green consumption values, Haws, Winterich, \& Naylor, 2014) have been proposed and studied as well. Due to their similarity, we include these other pro-environmental values concepts in our literature review and theory development.

According to Boomsma and Steg (2014), biospheric values correspond to the trans-situational belief that environmental protection is an important goal in life. Research suggests that biospheric values can be predictive of preferences for green products, intentions, and attitudes towards sustainable behavior, as well as environmentally relevant norms (see Steg \& de Groot, 2012 for a review). For example, holding biospheric values seems to be associated with a higher likelihood to report the consumption of organic food (Soyez, 2012) and the choice of environmentally friendly options (Haws et al., 2014). Relatedly, Steenkamp and de Jong (2010) found a positive relationship between the strength of a biospheric value orientation in individuals and their attitudes towards local products. Generally, biospheric values seem to comprise multiple motivations for green behavior and can therefore be a more global predictor of norms and intentions than other antecedents, such as concerns or worldviews (Steg, de Groot, Dreijerink, Abrahamse, \& Siero, 2011).
Despite the fast-growing literature on biospheric values and its consequences, our knowledge about the factors that facilitate the development of biospheric values in individuals is limited. This is also mirrored in the call for more research on how biospheric values can be strengthened (e.g., Steg \& de Groot, 2012). We propose that the self-nature connection paradigm can help us to better understand the formation of biospheric values.

\subsection{Self-nature connection and biospheric values}

Self-nature connection is defined as "the extent to which an individual includes nature within his/her cognitive representation of self" (Schultz, 2002, p. 67). In other words, self-nature connection is a feeling of connectedness to the natural environment and the notion that the natural environment is a defining element of who one is (Clayton \& Opotow, 2003).

We propose that a sense of connectedness to nature should facilitate the formation of biospheric values, a developmental process that spans potentially through an individual's entire life. Based on Leopold (1949), scholars argue that in order for humans to develop a sense of obligation to protect the environment, they need to feel that they are part of it (Dutcher, Finley, Luloff, \& Johnson, 2007; Mayer \& Frantz, 2004; Perkins, 2010). If somebody feels that she/he is part of nature, harming nature might be similar to harming oneself (Roszak, 1995). We therefore propose that individuals who feel connected to nature may regard the natural environment as an important aspect of their identity and may therefore be likely to form, over time, a trans-situational belief that protecting nature is desirable (i.e., a biospheric value orientation).

This theorizing is also compatible with the view of self-nature connection as a special form of social identity (Clayton, 2012a). Human and non-human life forms can be understood as two distinct groups with which individuals may or may not identify. The concept of self-nature connection (i.e., feeling part of nature) can be interpreted as a perceived affiliation with the non-human life form group (Crompton \& Kasser, 2009). It has been commonly found that people try to promote their own in-group (Tajfel \& Turner, 1986). Biospheric values can then be interpreted as the importance some individuals assign to promoting their in-group. This desire to promote the in-group (i.e., nature) can increase as perceived membership in the group (i.e., feeling part of nature) increases (Crompton \& Kasser, 2009, 2010; Levin \& Sidanius, 1999). In support of this proposition, researchers have found that a sense of connection to nature is positively associated with green values (e.g., Haws et al., 2014), self-reported pro-environmental behavior and intentions to behave pro-environmentally (e.g., Dutcher et al., 2007; Tam, 2013a), as well as environmental concern (e.g., Dutcher et al., 2007; Mayer \& Frantz, 2004; Schultz, 2001).

\subsection{Difference between self-nature connection and biospheric values}

Before we discuss our empirical approach to testing the proposed theoretical relationship between self-nature connection and biospheric values, it is important to note that we view them as related yet theoretically distinct constructs. Self-nature connection focuses on the role of nature in the self-concept. That is, nature and a feeling of a relationship with nature might for some people be defining elements of how they perceive themselves (Schultz, 2002). Biospheric values, on the other hand, concern the belief that environmental protection is an important goal pursuit in life (Boomsma \& Steg, 2014). According to these definitions, biospheric values (vs. self-nature connections) have a prominent focus on environmental care (Steg \& de Groot, 2012).

The view that self-nature connection and biospheric values are 
distinct constructs seems to be shared by the majority of the literature with a few exceptions (e.g., Dutcher et al., 2007). For example, in a recent comprehensive handbook on environmental psychology, environmental values and environmental identity were reviewed in separate chapters (Clayton, 2012b). Similarly, a comparative investigation of extant self-nature connection measures made a distinction between connection to nature and valuerelated concepts (Tam, 2013a). Relatedly, prior research has presented empirical evidence suggesting that it is possible to statistically distinguish between measures related to environmental care and measures related to self-nature connection (Sparks, Hinds, Curnock, \& Pavey, 2014).

While we theorize that a sense of connectedness to nature plays an important role in the formation of biospheric values, there may potentially be other factors which are not directly related to selfdefinition which also influence the formation of biospheric values. It is therefore possible that some individuals cultivate biospheric values without feeling connected to nature. Similarly, it is possible that some individuals feel connected to nature but do not develop strong biospheric values.

\subsection{Arguments for a relational path from biospheric values to self- nature connection}

On the basis of the reasoning presented above, we propose that the formation of self-nature connection in humans could be one of the mechanisms that can facilitate the development of biospheric values. However, there is also literature that suggests that biospheric values may form the basis of self-nature connection. In particular, extant research indicates that value orientations can foster the development of self-identities. For example, Hitlin (2003) found that value orientations formed the basis of personal role identities. Individuals who exhibited strong self-transcendent values (i.e., universalism and particularly benevolence) were more likely to develop a volunteering identity. Van der Werff, Steg, and Keizer $(2013 ; 2014)$ replicated these findings in the environmental domain. They found that biospheric values formed the basis of environmental self-identities. While these findings point towards a developmental path from values to some types of identities, we argue that they are not necessarily indicative of directionality regarding the self-nature connection - biospheric values relationship. Van der Werff and colleagues studied environmental self-identity (i. e., believing oneself to be a person with pro-environmental behavior) and clearly differentiated this concept from environmental identity defined as self-nature connection (Van der Werff et al., 2013). These two types of identities are conceptually different and findings regarding environmental self-identities may therefore not necessarily generalize to self-nature connections (Van der Werff et al., 2013).

\section{Empirical approach and overview of studies}

As stated above, our conceptual framework suggests a developmental process in which self-nature connection is associated with the adoption of biospheric values. In this framework, connectedness to nature and biospheric values are conceptualized as situationally stable constructs (Mayer \& Frantz, 2004; Steg \& de Groot, 2012). Such a theoretical standpoint precludes the use of methods involving the experimental manipulation of our focal constructs, at least as long as the experimental manipulations focus on short-term effects. Instead, we opted for a cross-sectional and quasi-experimental research approach, as explained below.

Assuming that observed environmental behavior can be a consequence of both concepts (Haws et al., 2014; Perkins, 2010), we can compare two alternative mediation paths (i.e., feeling connected to nature $\rightarrow$ biospheric values $\rightarrow$ behavior vs. biospheric values $\rightarrow$ feeling connected to nature $\rightarrow$ behavior; see Fig. 1). We do so in correlational Studies 1 and 2 . We are asking the two alternative questions: Are people characterized by high (vs. low) self-nature connection more likely to hold strong (vs. weak) biospheric values and therefore engage more in pro-environmental behavior? Or: Are people holding strong (vs. weak) biospheric values more likely to have high (vs. low) self-nature connection and therefore engage more in pro-environmental behavior? If our data support one path but not the other, we can draw statistical inferences about the directionality of the relationship between feelings of connectedness to nature and biospheric value orientations (see Tam, 2013b; Study 4 for a similar approach). In Study 3, we implement a quasi-experimental method (i.e., instrumental variable regression) to check if we can strengthen the directional propositions in our theoretical model.

In sum, Study 1 provides an initial test of our model in a broad online sample. In Study 2, we replicate the findings from Study 1 in a controlled laboratory setting, in different consumption contexts, and across different measures. In Study 3, we replicate the findings from Studies 1 and 2 with additional measures of self-nature connection, in additional behavioral contexts, and with a different method (i.e., instrumental variable regression).

\section{Study 1}

In Study 1, we intended to gather preliminary evidence to investigate the alternative paths of our theoretical model. To do so, we designed a cross-sectional survey measuring self-nature connection, biospheric values and pro-environmental behavior in a sample of online participants.

\subsection{Method}

\subsubsection{Participants and procedure}

Study 1 was part of a larger study introduced as a survey of personality characteristics. We recruited 512 US participants online through MTurk. We excluded 18 participants from the final analysis because they displayed a lack of motivation in their answers to open-ended questions or answering patterns to standardized item batteries. The final sample consisted of 494 participants (32\% male, age: average $=40$ years, $S D=12.6$ years, range $=13-75$ years $\left.{ }^{1}\right)$. In the beginning of the study, a number of unrelated measures were administered. Participants then completed a self-nature connection measure. After another battery of unrelated filler questions, environmentally relevant behavior was measured. At the end of the study, we measured participants' biospheric value orientation.

\subsubsection{Measures}

3.1.2.1. Self-nature connection. We used the Connection to Nature Scale (CNS; Mayer \& Frantz, 2004) as a measure of self-nature connection. The CNS is a widely used scale that showed good predictive validity in past research (e.g., Frantz \& Mayer, 2014; Tam, 2013a for reviews). Participants answered this 14-item scale on seven points ranging from $1=$ strongly disagree to $7=$ strongly agree. The scale showed good internal consistency $(\alpha=0.88)$.

3.1.2.2. Environmentally relevant behavior. In this task, participants were told that we were creating a campaign to make people aware of environmentally friendly behaviors that most people were not aware of. For this purpose, we needed their help. In particular, we

\footnotetext{
1 For all the studies, the authors have reported detailed information pertaining to all measures, data exclusions, and sample size determination.
} 


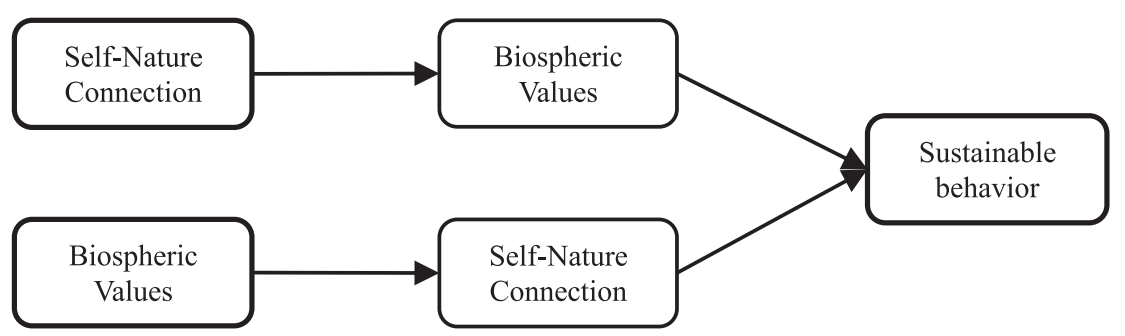

Fig. 1. Alternative paths used to investigate the directionality of the self-nature connection - biospheric values relationship.

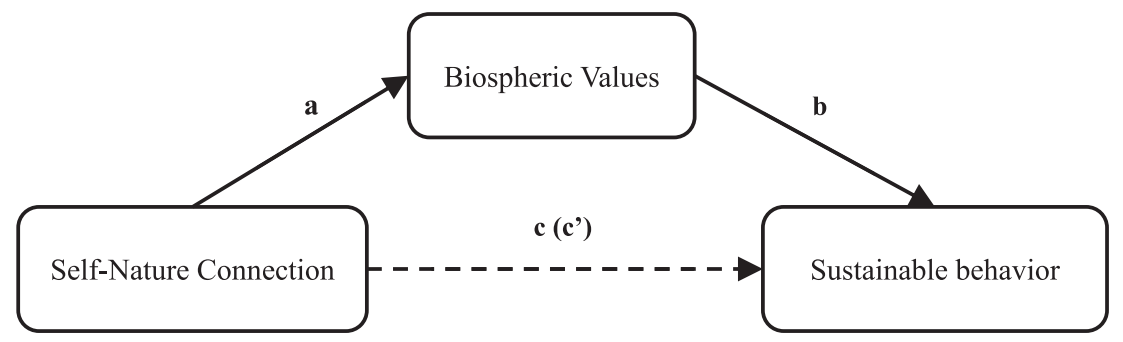

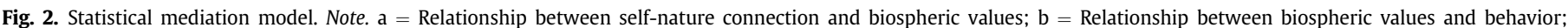

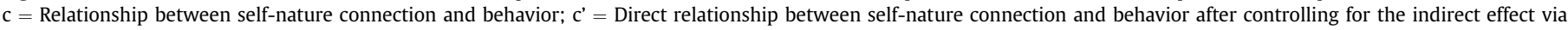
biospheric values.

asked participants to list all the environmentally friendly behaviors they could think of, thus helping us to identify environmentally relevant behaviors that are not well-known. Some of the most frequent answers included activities pertaining to recycling, turning off the light, and walking instead of taking the car. By helping us to create such an important campaign through their answers, the time and effort they spent on the task could be considered as measures of environmentally relevant behavior.

In order to determine whether the time and effort spent on this task represent, in the eyes of our participants, relevant behavior towards environmental protection, we analyzed whether participants perceived the task as useful on a scale from $1=$ extremely useless to $7=$ extremely useful. The mean usefulness rating $(M=5.3, S D=1.4)$ was significantly above the scale midpoint $(p<0.001)$. This arguably suggests that on average participants perceived that their work on the task was environmentally relevant. This is also mirrored in participants displaying noteworthy effort on the task, reporting on average 4.9 different behaviors $(S D=3.3)$ and spending an average of $143 \mathrm{~s}(S D=256)$ on the task. We therefore use the performance of our participants as an indicator of real environmentally relevant effort. To do so, we created a variable based on the number of environmentally friendly behaviors participants mentioned. In addition, we used the logtransformed time participants spent on our behavioral task.

3.1.2.3. Biospheric values. Biospheric values were measured with a single-item measure (i.e., "Are you generally willing to promote the environmental cause?'). This item was answered on a seven-point scale ranging from $1=$ not at all to $7=$ very much.

\subsection{Results}

\subsubsection{Discriminant validity}

The measures of interest (i.e., self-nature connection and biospheric values) are conceptually related. For this reason, it is important to establish their discriminant validity before conducting the main analyses. This was done by analyzing the bivariate correlation between these measures $(r=0.60 ; p<0.001)$. According to Brown (2006), a correlation coefficient of $r>0.8$ would have raised concerns about discriminant validity. The fact that we measured biospheric values with a single item prevented us from using more sophisticated procedures for investigating discriminant validity. In Studies 2 and 3, we will assess discriminant validity via a more common method suggested by Fornell and Larcker (1981).

\subsubsection{Connectedness to nature - biospheric values relationship}

We analyzed whether the data supported our theoretical model and compared these results to an alternative model to gain insight into the connectedness to nature - biospheric values relationship (see Fig. 1). The statistical model we used is visualized in Fig. 2. All mediation analyses in our studies were performed using the SPSS macro developed by Preacher and Hayes (2008). Following their

Table 1

Mediation models in Study 1.

\begin{tabular}{|c|c|c|c|c|c|c|c|c|}
\hline \multirow[t]{2}{*}{ Measure of self-nature connection } & \multirow[t]{2}{*}{ Coeff } & \multicolumn{4}{|l|}{ Paths } & \multirow[t]{2}{*}{ Indirect effect ${ }^{\mathrm{a}}$} & \multirow[t]{2}{*}{ Reversed indirect $\mathrm{t}^{\mathrm{b}}$} & \multirow[t]{2}{*}{$R^{2}$} \\
\hline & & $\mathrm{a}$ & $\mathrm{b}$ & c & $c^{\prime}$ & & & \\
\hline \multicolumn{9}{|c|}{ DV = Log-transformed time spent on the behavioral task } \\
\hline \multirow[t]{2}{*}{ CNS } & b & 0.83 & 0.17 & 0.26 & 0.12 & 0.14 & 0.05 & 0.07 \\
\hline & $\boldsymbol{p}$ & $<0.001$ & $<0.001$ & $<0.001$ & 0.06 & $<0.01$ & $<0.10$ & $<0.001$ \\
\hline \multicolumn{9}{|c|}{ DV = Number of ideas created on the behavioral task } \\
\hline \multirow[t]{2}{*}{ CNS } & $\boldsymbol{b}$ & 0.83 & 0.62 & 0.83 & 0.32 & 0.51 & 0.14 & 0.10 \\
\hline & $\boldsymbol{p}$ & $<0.001$ & $<0.001$ & $<0.001$ & 0.09 & $<0.01$ & $<0.10$ & $<0.001$ \\
\hline
\end{tabular}

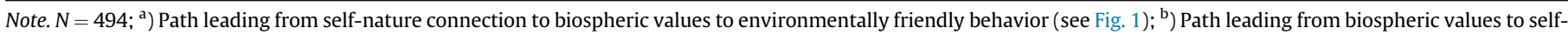
nature connection to environmentally friendly behavior (see Fig. 1); CNS = Connectedness to Nature; Please refer to Fig. 2 for an explanation of the model's paths. 
recommendations, the significance of indirect effects was tested with the bootstrapping method through 5000 bootstrap samples.

Using the number of ideas created and the time spent on the environmental task as measures of behavior, we ran two mediation models to assess the relationship between feelings of connectedness to nature and biospheric values (see Table 1). In both models, the path leading from self-nature connection through biospheric values to environmental behavior was significant. To gain further insight into the effect and its potential direction, we ran the models again, but this time with biospheric values as the independent variable and self-nature connection as the mediator. The path leading from biospheric values through self-nature connection to environmentally relevant behavior was not supported by our data.

\subsection{Discussion}

The results from Study 1 lend initial support to our theoretical reasoning. We found statistical evidence suggesting that biospheric value orientations may relate to a sense of connectedness to nature; biospheric value orientation then can be a motivating element of sustainable behavior. In statistical terms, biospheric values explained a substantial part of the relationship between self-nature connection and green behavior. This result indicates that feeling connected to nature may contribute to the development of biospheric values. In addition, we did not find evidence for a reverse relationship between biospheric values and self-nature connection.

These findings are encouraging, yet they are limited in several ways. First, we measured biospheric values with only a single-item question instead of a multi-item scale. Second, we measured selfnature connection with one specific measure - the Connectedness to Nature Scale (CNS, Mayer \& Frantz, 2004). Although the CNS scale is arguably the most popular measure of environmental identity among researchers, several other relevant tools have been proposed in the literature in the past ten years as well (see Tam, 2013a for a review). To increase the construct validity of our measures, it would be important to corroborate our initial findings with alternative assessments of biospheric values and self-nature connection.

Second, we focused our investigation on a relatively specific outcome domain (i.e., time and effort spent on generating ideas for a pro-environmental campaign). While we presented the scores on this measure as reflecting environmentally relevant effort by participants, it can be argued that this type of measure reflects the amount of knowledge with respect to sustainable behaviors rather than behavioral effort. ${ }^{2}$ Further evidence is needed to investigate whether our findings would generalize to more direct and specific behaviorally-relevant domains.

A third concern regarding our initial results may be the presence of common method variance. In particular, the fact that our two constructs of interest (i.e., feeling connected to nature and biospheric values) were self-reported by our participants might raise concerns about inflated relationships between these variables (Podsakoff, MacKenzie, Lee, \& Podsakoff, 2003). We believe that this is not a concern, since we are comparing two paths (i.e., selfnature connection $\rightarrow$ biospheric values $\rightarrow$ sustainable behavior vs. biospheric values $\rightarrow$ self-nature connection $\rightarrow$ sustainable behavior) and our data support the former but not the latter path. If present, common method variance should have affected both paths in the same way. Thus, we interpret the fact that only one of the two paths was supported by our data as evidence that common method

\footnotetext{
${ }^{2}$ The authors would like to thank an anonymous reviewer for highlighting this point.
}

variance is not a strong concern in Study 1 . Nevertheless, we will address this issue more directly in Study 3.

\section{Study 2}

Study 2 investigates the conceptual relationships outlined in our theoretical model (Fig. 2) by addressing some of the limitations of Study 1. First, we use a multi-item measure of biospheric values (in addition to a single item). Second, we use two different measures of self-nature connection (instead of one). Third, we use three shopping tasks (instead of effort on a sustainable campaign task) as behavioral measures to replicate our findings in a different, and more concrete behavioral domain. In terms of design, Study 2 uses a cross-sectional approach again but this time in a controlled laboratory setting (vs. online environment in Study 1).

\subsection{Method}

\subsubsection{Participants and procedure}

Study 2 was again part of a larger study for which 112 European participants were recruited from our university's student participant pool (see also Study 2a in Martin and Czellar, 2016). ${ }^{3}$ We excluded five participants due to insufficient language ability in the study language (i.e., English). In one of these five cases, problems with the language were self-reported, while in the other four cases, they were showcased in the amount of time these participants needed to complete the study. The final sample comprised 107 participants (age: average $=21$ years, $S D=2.8$ years, range $=$ 17-34 years; $65 \%$ male). After several unrelated tasks, participants completed three choice tasks which served as measures of sustainable behavior. Directly after these choices, our first measure of self-nature connection was administered (Inclusion of Nature in Self, INS, Schultz, 2001). After some additional tasks, participants completed the measures of biospheric values and the Connectedness to Nature scale (CNS, Mayer \& Frantz, 2004). Participants finished the session by answering additional questions regarding their choices, completing unrelated tasks and providing demographic information.

\subsubsection{Measures}

4.1.2.1. Self-nature connection. We used two different measures of self-nature connection: the CNS Scale $(\alpha=0.83)$ and the INS. This latter measure is a graphical single item. Participants are shown a series of seven pictures and are asked to indicate which picture best describes their relationship with the natural environment. Each picture consists of two circles, one representing the self and the other nature. The pictures vary in the extent to which the two circles overlap. The INS is widely used in the literature. Past research indicates that this measure has good predictive validity (Tam, 2013a).

4.1.2.2. Environmentally relevant behavior. In this study, we used scenario tasks to measure pro-environmental behavior. ${ }^{4}$ Participants were asked to imagine that they were shopping for different products (backpack, TV set, and coffee). Two alternative options for each product were introduced. One option was environmentally friendly while the other option was superior in different

\footnotetext{
${ }^{3}$ Due to different theoretical models, we analyzed the data in the two papers differently. We use mediation analysis to investigate the direction of paths between our variables of interest in the present research, while we used correlation analysis in Martin and Czellar (2016) to study differences in the size of correlations.

4 The scenarios were developed by Pia Furchheim (University of Lausanne). The authors would like to thank her for her permission to use the scenarios. An alternative version of the scenarios can be found in Furchheim (2016)
} 
performance categories compared to the environmentally friendly option. We did not explicitly label the relevant options as environmentally friendly. Rather, we included realistic cues in the product description of the different options that either indicated environmental friendliness or superior performance. Participants indicated their preference on a seven-point item $(1=$ definitely option $\mathrm{A} ; 7$ = definitely option B).

4.1.2.3. Biospheric values. Biospheric values were measured using the GREEN scale (Haws et al., 2014). This scale consists of six items and is designed to measure a biospheric value orientation in the consumer domain. The items were assessed on seven points (i.e., $1=$ not at all; $7=$ very much) and showed good internal consistency $(\alpha=0.90)$. In addition, we used the same single-item measure of biospheric values as in Study 1. In this study, the single-item measure was answered on a scale ranging from $0=$ not at all to $100=$ very much.

\subsection{Results}

\subsubsection{Discriminant validity}

Again, since both constructs of interest (i.e., self-nature connection and biospheric values) are conceptually related, it is important to establish discriminant validity between the different measures. First, the bivariate correlations between both self-nature connection measures (i.e., the CNS and INS) and the biospheric value measures were analyzed $\left(r_{\mathrm{CNS}}=0.53 ; p<0.001 ; r_{\mathrm{INS}}=0.54 ; p\right.$ $<0.001$ for the multi-item biospheric values measure and $r_{\mathrm{CNS}}=$ $0.48 ; p<0.001 ; r_{\text {INS }}=0.47 ; p<0.001$ for the single-item biospheric values measure). As in Study 1, the correlations were considerably below Brown's (2006) suggested limit of $r<0.8$. Second, we used a strategy suggested by Fornell and Larcker (1981; see also Farrell, 2010) to test discriminant validity based on confirmatory factor analysis. These authors suggest comparing the average variance explained (AVE) for each construct to the average shared variance (ASV) of the two constructs. Results suggest that the self-nature connection measure (CNS) and the biospheric values measure (GREEN) may capture distinct constructs as the AVE scores exceed the ASV score $\left(\mathrm{AVE}_{\mathrm{CNS}}=0.31 ; \mathrm{AVE}_{\mathrm{GREEN}}=0.61 ; \mathrm{ASV}_{\mathrm{CNSXGREEN}}=\right.$ 0.28 ). This test cannot be performed for the INS and for the second biospheric values measure due to their single-item nature.

\subsubsection{Connectedness to nature - biospheric values relationship}

Our data (i.e., two self-nature connection measures, two biospheric values measures, and three behavioral measures) allowed us to test our proposed theoretical model with 12 statistical models (see Tables 2a and 2b). Replicating the findings from Study 1, we found evidence for our proposed path (i.e., self-nature connection $\rightarrow$ biospheric values $\rightarrow$ sustainable behavior) in all 12 models. In addition, we reran the models with a reversed order of the constructs to test the alternative path (i.e., biospheric values $\rightarrow$ self-nature connection $\rightarrow$ sustainable behavior). This alternative path was not supported by our data.

\subsection{Discussion}

Similar to Study 1, we find evidence that biospheric values mediate the connectedness to nature - behavior link. This supports our theoretical model: a feeling of connection between self and nature may facilitate a stronger biospheric value orientation in individuals and this biospheric value orientation can motivate their environmentally friendly behavior. This finding is consistent across different measures of self-nature connection and biospheric values and holds for shopping choice tasks in different product categories. The results add to the findings from Study 1 through the use of a multi-item biospheric value measure, a different study population, and an alternative measure of green behavior compared to Study 1.

Taken together, these results lend further support to our model and indicate that an individual's sense of connectedness to nature could relate to the formation of biospheric values. This possibility emerges from both Studies 1 and 2, which were conducted in different countries using demographically different samples.

\section{Study 3}

The goal of this study was to test the proposed relationships in our theoretical model using a somewhat different research approach than in our previous two studies. We decided to gather additional evidence for our theoretical reasoning by collecting data on an instrumental variable. The instrumental variable approach is a specific type of quasi-experimental design suited for situations in which the manipulation of an independent variable is not relevant/ feasible. Our theoretical propositions pertain to a development process whereby the formation of an environmental identity can help the formation of biospheric values. The situational

Table 2a

Mediation models in Study 2 using the multi-item biospheric values measure.

\begin{tabular}{|c|c|c|c|c|c|c|c|c|}
\hline \multirow[t]{2}{*}{ Measure of self-nature connection } & \multirow[t]{2}{*}{ Coeff } & \multicolumn{4}{|c|}{ Paths } & \multirow[t]{2}{*}{ Indirect effect $^{\mathrm{a}}$} & \multirow[t]{2}{*}{ Reversed indirect ${ }^{\mathrm{b}}$} & \multirow[t]{2}{*}{$R^{2}$} \\
\hline & & a & $\mathrm{b}$ & c & $c^{\prime}$ & & & \\
\hline \multicolumn{9}{|c|}{ DV = Preference for eco-friendly over high-performing backpack } \\
\hline \multirow[t]{2}{*}{ CNS } & b & 0.75 & 0.67 & 0.60 & 0.09 & 0.50 & 0.04 & 0.17 \\
\hline & $\boldsymbol{p}$ & $<0.001$ & $<0.001$ & 0.01 & 0.71 & $<0.01$ & $>0.10$ & $<0.001$ \\
\hline \multirow[t]{2}{*}{ INS } & b & 0.52 & 0.55 & 0.57 & 0.29 & 0.29 & 0.16 & 0.19 \\
\hline & $\boldsymbol{p}$ & $<0.001$ & 0.003 & $<0.001$ & 0.10 & $<0.01$ & $>0.10$ & $<0.001$ \\
\hline \multicolumn{9}{|c|}{ DV = Preference for eco-friendly over high-performing coffee } \\
\hline \multirow[t]{2}{*}{ CNS } & b & 0.75 & 0.68 & 0.71 & 0.20 & 0.51 & 0.08 & 0.28 \\
\hline & $\boldsymbol{p}$ & $<0.001$ & $<0.001$ & $<0.001$ & 0.32 & $<0.01$ & $>0.10$ & $<0.001$ \\
\hline \multirow[t]{2}{*}{ INS } & b & 0.52 & 0.73 & 0.43 & 0.05 & 0.38 & 0.03 & 0.27 \\
\hline & $\boldsymbol{p}$ & $<0.001$ & $<0.001$ & 0.001 & 0.72 & $<0.01$ & $>0.10$ & $<0.001$ \\
\hline \multicolumn{9}{|c|}{ DV = Preference for eco-friendly over high-performing TV set } \\
\hline \multirow[t]{2}{*}{ CNS } & b & 0.75 & 0.56 & 0.62 & 0.20 & 0.42 & 0.08 & 0.14 \\
\hline & $\boldsymbol{p}$ & $<0.001$ & 0.003 & 0.009 & 0.44 & $<0.01$ & $>0.10$ & $<0.001$ \\
\hline \multirow[t]{2}{*}{ INS } & b & 0.52 & 0.62 & 0.35 & 0.03 & 0.32 & 0.02 & 0.13 \\
\hline & $\boldsymbol{p}$ & $<0.001$ & 0.001 & 0.03 & 0.88 & $<0.01$ & $>0.10$ & $<0.001$ \\
\hline
\end{tabular}

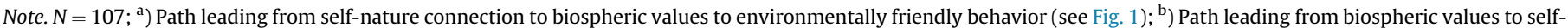

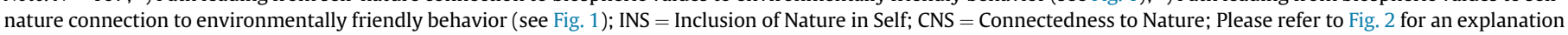
of the model's paths. 
Table 2b

Mediation models in Study 2 using the single-item biospheric values measure.

\begin{tabular}{|c|c|c|c|c|c|c|c|c|}
\hline \multirow[t]{2}{*}{ Measure of self-nature connection } & \multirow[t]{2}{*}{ Coeff } & \multicolumn{4}{|c|}{ Paths } & \multirow[t]{2}{*}{ Indirect effect ${ }^{\mathrm{a}}$} & \multirow[t]{2}{*}{ Reversed indirect ${ }^{\mathrm{b}}$} & \multirow[t]{2}{*}{$R^{2}$} \\
\hline & & a & $\mathrm{b}$ & c & $c^{\prime}$ & & & \\
\hline \multicolumn{9}{|c|}{ DV = Preference for eco-friendly over high-performing backpack } \\
\hline \multirow[t]{2}{*}{ CNS } & b & 15.66 & 0.03 & 0.60 & 0.20 & 0.40 & 0.00 & 0.15 \\
\hline & $\boldsymbol{p}$ & $<0.001$ & 0.001 & 0.01 & 0.43 & $<0.01$ & $>0.10$ & $<0.001$ \\
\hline \multirow[t]{2}{*}{ INS } & b & 10.43 & 0.02 & 0.57 & 0.35 & 0.22 & 0.01 & 0.18 \\
\hline & $\boldsymbol{p}$ & $<0.001$ & 0.006 & $<0.001$ & 0.04 & $<0.01$ & $<0.10$ & $<0.001$ \\
\hline \multicolumn{9}{|c|}{ DV = Preference for eco-friendly over high-performing coffee } \\
\hline \multirow[t]{2}{*}{ CNS } & $\boldsymbol{b}$ & 15.66 & 0.02 & 0.71 & 0.32 & 0.39 & 0.00 & 0.24 \\
\hline & $\boldsymbol{p}$ & $<0.001$ & $<0.001$ & $<0.001$ & 0.11 & $<0.01$ & $>0.10$ & $<0.001$ \\
\hline \multirow[t]{2}{*}{ INS } & b & 10.43 & 0.03 & 0.43 & 0.15 & 0.27 & 0.00 & 0.23 \\
\hline & $\boldsymbol{p}$ & $<0.001$ & $<0.001$ & 0.001 & 0.27 & $<0.01$ & $>0.10$ & $<0.001$ \\
\hline \multicolumn{9}{|c|}{ DV = Preference for eco-friendly over high-performing TV set } \\
\hline \multirow[t]{2}{*}{ CNS } & b & 15.66 & 0.03 & 0.62 & 0.18 & 0.44 & 0.00 & 0.17 \\
\hline & $\boldsymbol{p}$ & $<0.001$ & $<0.001$ & 0.009 & 0.47 & $<0.01$ & $>0.10$ & $<0.001$ \\
\hline \multirow[t]{2}{*}{ INS } & b & 10.43 & 0.03 & 0.35 & 0.03 & 0.31 & 0.00 & 0.17 \\
\hline & $\boldsymbol{p}$ & $<0.001$ & $<0.001$ & 0.03 & 0.85 & $<0.01$ & $>0.10$ & $<0.001$ \\
\hline
\end{tabular}

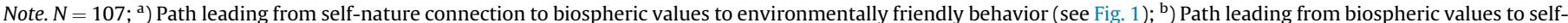

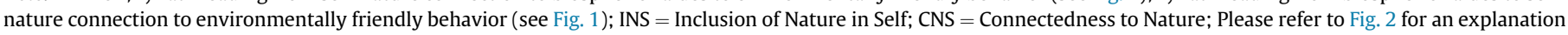
of the model's paths.

manipulation of environmental identity through between-subjects, random assignment to low-vs. high treatment conditions is not compatible with this long-term process. However, we can envision identifying a natural variable (i.e., an instrumental variable) that would account for some part of the long-term variations of environmental identity levels between participants and use this instrumental variable to identify variance in our environmental identity measures that is due to this natural (exogenous) cause. We then use this (exogenous) part of the variance to test our proposition regarding the self-nature connection - biospheric values relationship. We adopted this methodological strategy in Study 3.

We also wished to separate the measures for the different constructs in our theoretical model as much as possible. For this reason, we divided this study into two parts that were conducted two weeks apart (a lab session and an online follow-up questionnaire). In addition, we used another type of behavioral measure and a third type of connectedness to nature measure to increase the generalizability of our findings. Last, we wished to increase the predictive validity of our model by using a pro-environmental donation task involving financial spending.

\subsection{Method}

\subsubsection{Participants and procedure}

We recruited 317 European participants from our university's participant pool. We excluded seven participants due to technical difficulties (i.e., the survey software crashed and participants had to restart the questionnaire at the beginning) and four participants due to insufficient proficiency in the study language (i.e., English). In addition, ten participants were excluded because they had ignored the instructions and left their PCs to discuss their responses with other participants and one participant because she had taken part in a related pilot study. The initial sample therefore consisted of 295 participants. As part of a larger study, we first collected several self-nature connection measures. Behavioral measures were then collected after several unrelated personality measures and tasks (i.e., approximately 15 min later). The instrumental variable for our quasi-experiment was collected at the end of the session together with the demographics. Biospheric values and a donation task involving real money were included in the online follow-up study, which participants completed two weeks after the initial lab study. Our final sample consisted of 271 participants (53\% male, age: average $=21$ years, $S D=2.3$ years, range $=17-33$ years $)$ because not all participants completed the online follow-up questionnaire. There was no systematic evidence for selection bias due to non-participation in the follow-up.

\subsubsection{Measures}

5.1.2.1. Self-nature connection. In addition to the Connectedness to Nature scale (CNS, $\alpha=0.80$ ) used in Studies 1 and 2, and the Inclusion of Nature in Self scale (INS) used in Study 2, we also included the Love and Care for Nature scale (LCN; Perkins, 2010). It comprised 15 items that were rated on seven points $(1=$ strongly disagree; $7=$ strongly agree, $\alpha=0.94)$. While the CNS Scale and the INS are arguably cognitive measures (Perrin \& Benassi, 2009; Tam, 2013a), the LCN Scale may capture connectedness to nature on a more emotional level. The LCN has shown good criterion validity in past research (e.g., Hoffarth \& Hodson, 2016; Tam, 2013a). We also included the Nature Relatedness scale (Nisbet, Zelenski, \& Murphy, 2009) in this study. However, as will be discussed below, this scale failed to discriminate from our biospheric values measure.

5.1.2.2. Environmentally relevant behavior. Environmentally relevant behavior was assessed with four different types of tasks. As in Studies 1 and 2, all measures were intended to be used in our mediation models. First, we used the same behavioral task as in Study 1. Participants again perceived our campaign in the behavioral task as useful on a scale from $1=$ extremely useless to 7 = extremely useful $(M=5.3 ; S D=1.3$, significantly above the midpoint, $p<0.001$ ). This suggests that on average participants perceived that their work on our task was environmentally relevant. We therefore use performance on this task (i.e., number of ideas created and log-transformed time spent) as an indicator of environmentally relevant behavior. The mean time spent on the task was $264 \mathrm{~s}(S D=153 \mathrm{~s})$. Participants created 6.6 ideas on average $(S D=2.6)$. Some of the most commonly mentioned activities pertained to recycling and buying environmentally friendly products.

Second, we included a measure of self-reported past environmental behavior adopted from Tam (2013a). This measure consists of 12 environmentally friendly behaviors (e.g., purchasing products in reusable containers). Participants were asked to indicate how often they had performed these behaviors in the past $(1=$ never; 7 = very often). This measure was included to capture environmentally relevant behavior in a general sense (i.e., comprising multiple behavioral domains, such as consumption, purchasing 
behavior and activism).

Third, we used three scenario tasks. Two of the three shopping tasks (i.e., shopping for a phone and shoes) were similar to the tasks in Study 2. This time, however, participants did not indicate their preferences on a seven-point item scale, but were asked to make discrete choices. The third scenario task (i.e., willingness to pay for an eco-friendly version of a dishwashing soap) was adopted from Luchs, Naylor, Irwin, and Raghunathan (2010). In this task, participants were asked to imagine that a well-known producer of cleaning products is considering launching a new version of a popular dishwashing soap. The classic version of this soap costs the equivalent of USD 3.95. Participants were then asked to indicate how much they would be willing to pay for an eco-friendly version of this product. In the scenario, the eco-friendly version is equal in all performance aspects, but is certified to be more environmentally friendly than the original version of the product.

Fourth, we administered a donation task involving real money. Participants had a chance to win the equivalent of 100 US dollars if they completed our follow-up survey. At the end of the survey, we asked participants if they were willing to donate a portion of their prize money to the World Wildlife Fund for Nature (WWF) should they be drawn to win, and if so, how much they wanted to donate. We also informed them that we would donate the money on their behalf and that they would receive only the amount they had not donated. This was indeed the case. We donated the amount the winners had indicated and paid them only the amount that was left from their prize. Furthermore, the winners received a confirmation of their donation issued by the WWF. The amount donated to the WWF served as another measure of real behavior.

5.1.2.3. Biospheric values. Biospheric values were measured using the GREEN scale (Haws et al., 2014) previously used in Study 2 and the single-item biospheric values measure from Study 1 . The GREEN scale showed good internal consistency $(\alpha=0.91)$.

5.1.2.4. Instrumental variable. We used instrumental variable regression to investigate the connectedness to nature - biospheric value relationship more directly. In general, instrumental variable regression requires a meaningful instrumental variable (see Angrist \& Pischke, 2009). Specifically, the instrumental variable needs to correlate with self-nature connection and be exogenous (i.e., should not be dependent on any unobserved factors in the model). In addition, the instrumental variable must correlate with the dependent variable (i.e., biospheric values) only through its effect on the predictor variable (i.e., self-nature connection). We chose information on where a person grew up as an instrumental variable. This was measured with a single 11-point item. The item read "Please tell us in which environment you spent most of your time when you were a kid" ( 0 = rural area; 10 = big city).

We argue that whether a participant grew up in a rural or urban setting fulfills the criteria of a good instrumental variable. Individuals who grew up in a rural (urban) environment should have had more (less) exposure to nature and should therefore feel more (less) connected to the natural environment (Hinds \& Sparks, 2008). In addition, the environment in which one grows up is most often independent of the person's will.

\subsection{Results}

\subsubsection{Discriminant validity}

Before the main analyses, we investigated discriminant validity by comparing correlation coefficients to the 0.8 threshold (Brown, 2006) and by checking whether the AVE exceeded the ASV (Fornell \& Larcker, 1981). All self-nature connection measures (i.e., Inclusion of Self in Nature, INS; Connectedness to Nature scale, CNS;
Table 3

Discriminant validity of multi-item measures in Study 3.

\begin{tabular}{llll}
\hline \multicolumn{2}{l}{$\begin{array}{l}\text { Self-nature connection and } \\
\text { environmental behavior }\end{array}$} & GREEN & \\
\cline { 1 - 2 } Measure & AVE $^{\mathrm{a}}$ & & ASV $^{\mathrm{b}}$ \\
\cline { 2 - 3 } CNS & 0.266687 & 0.618725 & 0.246115 \\
LCN & 0.530829 & 0.619284 & 0.362404 \\
NR & 0.262851 & 0.618923 & 0.462264 \\
Past behaviour & 0.263901 & 0.618673 & 0.383161 \\
\hline
\end{tabular}

Note. ${ }^{a}$ ) Average variance explained; ${ }^{b}$ ) Average shared variance; CNS = Connectedness to Nature; LCN = Love and Care for Nature; NR = Nature Relatedness, GREEN $=$ Biospheric values.

Love and Care for Nature, LCN; Nature Relatedness, NR) correlated significantly with the multi-item biospheric value measure (i.e., $r_{\mathrm{INS}}=0.52 ; r_{\mathrm{CNS}}=0.50 ; r_{\mathrm{LCN}}=0.60 ; r_{\mathrm{NR}}=0.68$, all $\left.p<0.001\right)$ and the single-item biospheric value measure (i.e., $r_{\text {INS }}=0.50$; $r_{\mathrm{CNS}}=0.52 ; r_{\mathrm{LCN}}=0.58 ; r_{\mathrm{NR}}=0.67$, all $p<0.001$ ), but no correlation exceeded the threshold suggested by Brown (2006). While the CNS and the LCN passed the Fornell and Larcker (1981) criterion, the NR failed it (see Table 3). This was due to a relatively low average variance explained rather than due to an excessively large average shared variance. Nonetheless, due to this discriminant validity issue, this scale was excluded from further analyses. The selfreported measure of past behavior (Tam, 2013a) also failed to meet the Fornell and Larcker (1981) criterion and was therefore also excluded from further analyses.

\subsubsection{Connectedness to nature - biospheric value relationship}

The data allowed us to investigate the relationship between selfnature connection and biospheric values, using the methods outlined in Section 2. First, we ran 36 different models where we compared the proposed self-nature connection $\rightarrow$ biospheric values $\rightarrow$ behavior path to its biospheric values $\rightarrow$ self-nature connection $\rightarrow$ behavior counterpart. Each model is a unique combination of one of the three self-nature connection measures with one of the two biospheric value measures and one of the six behavioral measures. The full results are included in Tables A1a A.2b in the Appendix. The general pattern of results resembles the findings in Studies 1 and 2. Generally, we find support for the proposed path leading from connectedness to nature through biospheric values to behavior. This path is statistically significant in 33 of our 36 models. This provides evidence for our reasoning that connectedness to nature may foster the development of biospheric values. In contrast, an alternative path (i.e., biospheric values $\rightarrow$ connectedness to nature $\rightarrow$ behavior) is supported in only six of our 36 models. Interestingly, in five of these six models, both paths (see Fig. 1) are supported by our data. In four of these six models, our results indicate that the connectedness to nature $\rightarrow$ biospheric values $\rightarrow$ behavior path is the stronger of the two paths.

Second, to gain more insight into the self-nature connection biospheric values relationship, we used a method widely used in economics - instrumental variable regression (Antonakis, Bendahan, Jacquart, \& Lalive, 2010). Instrumental variable regression is a statistical method utilizing a variable that is as good as randomly assigned (i.e., where an individual grew up in our case) to estimate the variance in self-nature connection that is unrelated to the model's error term. This estimated variance of self-nature connection, rather than its full variance, is then used to estimate the relationship between self-nature connection and biospheric values (Angrist \& Pischke, 2009).

In our case, the environment where a participant grew up predicted a person's self-nature connection significantly yet weakly. This caused the first-stage F-statistic (Tables $4 \mathrm{a}$ and $4 \mathrm{~b}$ ) to be 
Table 4a

Instrumental variable regression with grew up (rural vs. urban area) variable as the instrumental variable (Study 3).

\begin{tabular}{lll}
\hline & First stage & Effect of self-nature connection on biospheric values $^{\text {a }}$ \\
\hline INS & $F(1,268)=16.91$ & $\beta=0.41 ; p=0.03$ \\
CNS & $F(1,268)=7.43$ & $\beta=0.92 ; p=0.04$ \\
LCN & $F(1,268)=5.72$ & $\beta=0.81 ; p=0.03$ \\
\hline
\end{tabular}

Note. ${ }^{\text {a }}$ ) Biospheric values measured using the multi-item measure (Haws et al., 2014); INS = Inclusion of Nature in Self; CNS = Connectedness to Nature; LCN = Love and Care for Nature.

Table 4b

Instrumental variable regression with grew up (rural vs. urban area) variable as the instrumental variable (Study 3 ).

\begin{tabular}{lll}
\hline & First stage & Effect of self-nature connection on biospheric values $^{\mathrm{a}}$ \\
\hline INS & $F(1,268)=16.91$ & $\beta=7.57 ; p=0.10$ \\
CNS & $F(1,268)=7.43$ & $\beta=17.07 ; p=0.09$ \\
LCN & $F(1,268)=5.72$ & $\beta=15.15 ; p=0.07$ \\
\hline
\end{tabular}

Note. ${ }^{\text {a) }}$ Biospheric values measured using the single-item measure (see Study 1); INS = Inclusion of Nature in Self; CNS = Connectedness to Nature; $\mathrm{LCN}=$ Love and Care for Nature.

smaller than the recommended minimum value of 10 (Staiger \& Stock, 1997) in several of our models. However, the classic instrumental variable estimator (i.e., two-stage least squares) has been demonstrated to be approximately unbiased if there is only one instrument (i.e., where a person grew up) and one endogenous variable (i.e., self-nature connection) even if the first-stage statistic is relatively weak (Angrist \& Pischke, 2009).

Generally, we find a positive effect of self-nature connection on biospheric values in our models using the multi-item biospheric value scale (Table 4a). This finding further supports our proposition that a sense of connectedness is related to biospheric values. The effect is similar, though only marginally significant, in the models using the single-item biospheric value measure (Table 4b).

\subsection{Discussion}

In Study 3, we found further support for our theoretical model indicating that a feeling of connectedness to nature can contribute to the development of a biospheric value orientation. A biospheric value orientation seems to serve as a mediating force between environmental identity and sustainable behavior. The findings of this study are noteworthy for several reasons. First, they hold across several different measures of self-nature connection and biospheric values. The findings are consistent across several domains of behavior, and we replicated them with different empirical methods. Moreover, we collected the biospheric value measures several weeks after the other measures thus minimizing the possibility of an overall demand effect during the study. Additionally, because the quasi-experimental method employed is relatively immune to common method bias, it also helps to rule out that common method variance accounts for our findings (Antonakis et al., 2010).

While the findings based on the two biospheric value measures are globally similar, two noteworthy differences emerged between the multi-item and single-item measures in Study 3. First, the single-item measure produced findings consistent with our theoretical model with regards to donations to an environmental organization (i.e., the WWF). The multi-item biospheric value measure, on the other hand, did not produce a clear directional pattern (i.e., we find equal support for both paths) in two of the three models based on our donation task. We think that this is because the single-item measure is broader in its focus on environmental protection in general, while the multi-item measure is focused more on the consumption domain. In other words, it could be argued that donation is not a traditional type of consumption behavior and might therefore be beyond the scope of the Haws et al. (2014) values measure. Following the same logic, this latter measure seems to be a better predictor of our consumptionoriented behavioral measures compared to the single-item biospheric value measure.

Second, we find support for our proposed model in the quasiexperiment with the multi-item biospheric value measure. The instrumental variable regression findings utilizing the single-item measure, on the other hand, are only marginally significant. One potential explanation is that the single-item measure could have been more susceptible to measurement error (Salzberger, 2007) and might generally be less precise than multi-item measures (Diamantopoulos, Sarstedt, Fuchs, Wilczynski, \& Kaiser, 2012). This problem might have been magnified by the relatively weak F-statistics in the first stage of our instrumental variable regression models.

\section{General discussion}

Our research adopts a predominantly cognitive perspective of the individual and theorizes that a sense of connection to nature can contribute to the development of his/her biospheric value orientation. Our three studies converge in suggesting that selfnature connection positively relates to biospheric values and that biospheric values mediate the relationship between self-nature connection and environmentally friendly behavior. The statistical evidence is based on several behavioral tasks in different environmental domains. These findings are accompanied by quasiexperimental results that also corroborate the proposed conceptual linkages. Moreover, the findings hold in online and laboratory settings, with both US (non-student) and European (student) samples, and across several operationalizations of connectedness to nature and biospheric values.

A general concern regarding our research could be the presence of omitted variable bias. It could be possible that the found effects can be explained by developmental variables (e.g., socialization processes) that may simultaneously influence self-nature connection and biospheric values. However, the pattern of our results speaks against such an explanation. If there might be a common omitted correlate of self-nature connection and biospheric values, we would have found equally strong support for the self-nature connection $\rightarrow$ biospheric values path and the biospheric values $\rightarrow$ self-nature connection path in our model. In addition, we used instrumental variable regression (i.e., a technique argued to be robust against omitted variable bias; Antonakis et al., 2010) to replicate our findings and found support for the self-nature 
connection $\rightarrow$ biospheric values path.

On a few occasions, we found evidence for effects in both statistical directions (i.e., from self-nature connection to biospheric values and also from biospheric values to self-nature connection). This could indicate that feedback loops may occur in the process of biospheric value development. Even though this evidence is nonsystematic, it would be important to explore if there could be certain personal or environmental conditions under which such feedback loops are more (less) likely to emerge. The possibility of feedback loops would be in line with findings showing that past behavior can influence future behavior, environmental attitudes, self-image (Cornelissen, Pandelaere, Warlop, \& Dewitte, 2008), as well as environmental self-identity (Van der Werff et al., 2014). The predominantly cross-sectional designs used in our three studies do not allow us to investigate these dynamic aspects of the developmental processes related to one's environmental identity. We therefore encourage future research to design longitudinal studies, spanning potentially over several years, to investigate how individual environmental identity, biospheric values and sustainable behaviors co-evolve as a result of particular personal factors and environmental conditions.

Even though biospheric values are an important concept in the literature, this set of studies is the first, to our knowledge, to link the literature streams on self-nature connection and biospheric values, which have emerged relatively independently of each other. Our findings have therefore several theoretical and practical implications. First, they may serve as the first step in developing a more comprehensive understanding of how nature influences the development of judgment and decision making processes. Our findings suggest that individuals who have integrated nature in their self-concepts may possibly adopt biospheric value orientations. Therefore, it is possible that these individuals will judge social phenomena, such as policy initiatives (Boomsma \& Steg, 2014) and global vs. local products (Steenkamp \& de Jong, 2010) differently from individuals who have not integrated nature in the selfconcept. Second, holding biospheric values can be a mediating factor between self-nature connection and pro-environmental behaviors. This finding can help explain, at least in part, why past research has often found a positive relationship between measures of environmental identity and assessments of pro-environmental behavior (Clayton, 2012a).

Third, by investigating how self-nature connection and biospheric values relate to each other, our research has implications for social marketers and policy makers who wish to encourage sustainable behavior in individuals. Our data suggest that individuals in rural (vs. urban) areas develop stronger (vs. weaker) sense of connectedness with nature (see also Hinds \& Sparks, 2008). Social marketers and policy makers may want to enable/ encourage urban children and adults to (re)connect with nature as this process may be conducive to the development of biospheric values. This can be done, for example, through environmental education (e.g., Collado, Staats, \& Corraliza, 2013), exposing city dwellers to nature (e.g., through parks and urban green spaces; e.g., Mayer, Frantz, Bruehlman-Senecal, \& Dolliver, 2009), or fostering a personified perception of nature (Tam, Lee, \& Chao, 2013). We also think that in order to be effective in influencing identities and values, such efforts need to be implemented as part of long-term education programs. These might be particularly promising ways to encourage pro-environmental behavior as the cultivation of biospheric values can not only have direct behavioral consequences, but may also appear to determine whether environmental communication is effective in increasing sustainable behavior (Bolderdijk, Gorsira, Keizer, \& Steg, 2013).

\section{Acknowledgements}

This research was supported by grant No. 100018_137974 from the Swiss National Science Foundation. The authors would like to thank Bruno Kocher, Arnd Florack, and three anonymous reviewers for their helpful comments on earlier versions of this manuscript. The SNSF was not involved in the reported research project other than by providing funding.

The authors declare that there has not been any actual or potential conflict of interests related to this research.

\section{Appendix}

Table A.1a

Mediation models in Study 3 based on real behavior (based on the multi-item biospheric values measure; Haws et al., 2014).

\begin{tabular}{|c|c|c|c|c|c|c|c|c|}
\hline \multirow[t]{2}{*}{ Measure of self-nature connection } & \multirow[t]{2}{*}{ Coeff } & \multicolumn{4}{|l|}{ Paths } & \multirow[t]{2}{*}{ Indirect effect $^{\mathrm{a}}$} & \multirow[t]{2}{*}{ Reversed indirect $^{\mathrm{b}}$} & \multirow[t]{2}{*}{$R^{2}$} \\
\hline & & $\mathrm{a}$ & $\mathrm{b}$ & c & $c^{\prime}$ & & & \\
\hline \multicolumn{9}{|c|}{ DV = Log-transformed time spent on the behavioral task } \\
\hline \multirow[t]{2}{*}{ INS } & $\boldsymbol{b}$ & 0.47 & 0.10 & 0.13 & 0.08 & 0.05 & 0.05 & 0.08 \\
\hline & $\boldsymbol{p}$ & $<0.001$ & 0.01 & $<0.001$ & 0.03 & $<0.01$ & $<0.05$ & $<0.001$ \\
\hline \multirow[t]{2}{*}{ CNS } & b & 0.67 & 0.14 & 0.11 & 0.01 & 0.10 & 0.01 & 0.06 \\
\hline & $\boldsymbol{p}$ & $<0.001$ & $<0.001$ & 0.02 & 0.79 & $<0.01$ & $>0.10$ & $<0.001$ \\
\hline \multirow[t]{2}{*}{ LCN } & b & 0.64 & 0.18 & 0.06 & -0.05 & 0.11 & -0.03 & 0.07 \\
\hline & $\boldsymbol{p}$ & $<0.001$ & $<0.001$ & 0.11 & 0.24 & $<0.01$ & $>0.10$ & $<0.001$ \\
\hline \multicolumn{9}{|c|}{ DV = Number of ideas created on the behavioral task } \\
\hline \multirow[t]{2}{*}{ INS } & $\boldsymbol{b}$ & 0.47 & 0.51 & 0.23 & -0.01 & 0.24 & -0.00 & 0.04 \\
\hline & $\boldsymbol{p}$ & $<0.001$ & 0.003 & 0.08 & 0.96 & $<0.01$ & $>0.10$ & 0.003 \\
\hline \multirow[t]{2}{*}{ CNS } & b & 0.67 & 0.47 & 0.42 & 0.10 & 0.32 & 0.04 & 0.04 \\
\hline & $\boldsymbol{p}$ & $<0.001$ & 0.006 & 0.04 & 0.67 & $<0.05$ & $>0.10$ & 0.003 \\
\hline \multirow[t]{2}{*}{ LCN } & $\boldsymbol{b}$ & 0.64 & 0.57 & 0.25 & -0.12 & 0.37 & -0.07 & 0.04 \\
\hline & $\boldsymbol{p}$ & $<0.001$ & 0.002 & 0.12 & 0.55 & $<0.01$ & $>0.10$ & 0.002 \\
\hline \multicolumn{9}{|c|}{ DV $=$ Amount of money donated $(N=269)$} \\
\hline \multirow[t]{2}{*}{ INS } & $\boldsymbol{b}$ & 0.47 & 3.17 & 2.29 & 0.81 & 1.48 & 0.47 & 0.04 \\
\hline & $\boldsymbol{p}$ & $<0.001$ & 0.01 & 0.02 & 0.47 & $<0.01$ & $>0.10$ & 0.003 \\
\hline \multirow[t]{2}{*}{ CNS } & b & 0.67 & 2.41 & 5.02 & 3.40 & 1.63 & 1.23 & 0.06 \\
\hline & $\boldsymbol{p}$ & $<0.001$ & 0.05 & $<0.001$ & 0.04 & $<0.05$ & $<0.05$ & $<0.001$ \\
\hline \multirow[t]{2}{*}{ LCN } & b & 0.64 & 2.19 & 3.98 & 2.57 & 1.41 & 1.46 & 0.05 \\
\hline & $\boldsymbol{p}$ & $<0.001$ & 0.10 & $<0.001$ & 0.07 & $<0.10$ & $<0.10$ & $<0.001$ \\
\hline
\end{tabular}

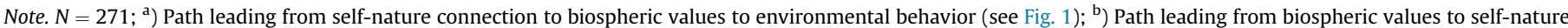

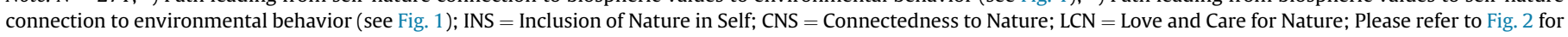
an explanation of the model's paths. 
Table A.1b

Mediation models in Study 3 based on real behavior (based on the single-item biospheric values measure from Study 1)

\begin{tabular}{|c|c|c|c|c|c|c|c|c|}
\hline \multirow[t]{2}{*}{ Measure of self-nature connection } & \multirow[t]{2}{*}{ Coeff } & \multicolumn{4}{|l|}{ Paths } & \multirow[t]{2}{*}{ Indirect effect ${ }^{\mathrm{a}}$} & \multirow[t]{2}{*}{ Reversed indirect ${ }^{\mathrm{b}}$} & \multirow[t]{2}{*}{$R^{2}$} \\
\hline & & $\mathrm{a}$ & $\mathrm{b}$ & c & $c^{\prime}$ & & & \\
\hline \multicolumn{9}{|c|}{ DV = Log-transformed time spent on the behavioral task } \\
\hline \multirow[t]{2}{*}{ INS } & b & 10.39 & 0.00 & 0.13 & 0.10 & 0.03 & 0.00 & 0.07 \\
\hline & $\boldsymbol{p}$ & $<0.001$ & 0.11 & $<0.001$ & 0.006 & $<0.10$ & $<0.05$ & $<0.001$ \\
\hline \multirow[t]{2}{*}{ CNS } & b & 16.56 & 0.00 & 0.11 & 0.04 & 0.07 & 0.00 & 0.04 \\
\hline & $\boldsymbol{p}$ & $<0.001$ & 0.01 & 0.02 & 0.51 & $<0.01$ & $>0.10$ & 0.003 \\
\hline \multirow[t]{2}{*}{ LCN } & b & 14.46 & 0.01 & 0.06 & -0.02 & 0.08 & -0.00 & 0.04 \\
\hline & $\boldsymbol{p}$ & $<0.001$ & 0.003 & 0.11 & 0.67 & $<0.01$ & $>0.10$ & 0.003 \\
\hline \multicolumn{9}{|c|}{ DV = Number of ideas created on the behavioral task } \\
\hline \multirow[t]{2}{*}{ INS } & b & 10.39 & 0.02 & 0.23 & 0.04 & 0.19 & 0.00 & 0.04 \\
\hline & $p$ & $<0.001$ & 0.01 & 0.08 & 0.80 & $<0.01$ & $>0.10$ & 0.008 \\
\hline \multirow[t]{2}{*}{ CNS } & b & 16.56 & 0.02 & 0.42 & 0.13 & 0.29 & 0.00 & 0.04 \\
\hline & $p$ & $<0.001$ & 0.02 & 0.04 & 0.59 & $<0.05$ & $>0.10$ & 0.008 \\
\hline \multirow[t]{2}{*}{$\mathrm{LCN}$} & b & 14.46 & 0.02 & 0.25 & -0.05 & 0.30 & -0.00 & 0.04 \\
\hline & $p$ & $<0.001$ & 0.008 & 0.12 & 0.79 & $<0.01$ & $>0.10$ & 0.008 \\
\hline \multicolumn{9}{|c|}{ DV $=$ Amount of money donated $(N=269)$} \\
\hline \multirow[t]{2}{*}{ INS } & b & 10.41 & 0.18 & 2.29 & 0.38 & 1.90 & 0.01 & 0.06 \\
\hline & $\boldsymbol{p}$ & $<0.001$ & $<0.001$ & 0.02 & 0.72 & $<0.01$ & $>0.10$ & $<0.001$ \\
\hline \multirow[t]{2}{*}{ CNS } & b & 16.62 & 0.15 & 5.02 & 2.51 & 2.51 & 0.04 & 0.07 \\
\hline & $\boldsymbol{p}$ & $<0.001$ & 0.004 & $<0.001$ & 0.14 & $<0.01$ & $<0.10$ & $<0.001$ \\
\hline \multirow[t]{2}{*}{$\mathrm{LCN}$} & b & 14.70 & 0.15 & 3.98 & 1.78 & 2.21 & 0.04 & 0.07 \\
\hline & $\boldsymbol{p}$ & $<0.001$ & 0.008 & $<0.001$ & 0.20 & $<0.01$ & $>0.10$ & $<0.001$ \\
\hline
\end{tabular}

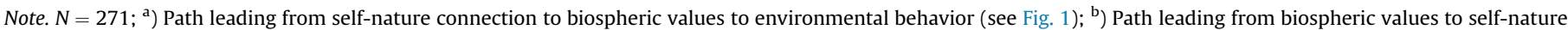

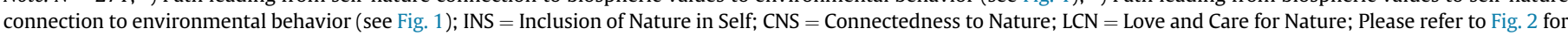
an explanation of the model's paths.

Table A.2a

Mediation models in Study 3 based on hypothetical choices (based on the multi-item biospheric values measure; Haws et al., 2014)

\begin{tabular}{|c|c|c|c|c|c|c|c|c|}
\hline \multirow{2}{*}{ Measure of self-nature connection } & \multirow{2}{*}{ Coeff } & \multicolumn{4}{|l|}{ Paths } & \multirow{2}{*}{ Indirect effect ${ }^{\mathrm{a}}$} & \multirow{2}{*}{ Reversed indirect $^{\mathrm{b}}$} & \multirow{2}{*}{$R^{2}$} \\
\hline & & $\mathrm{a}$ & $\mathrm{b}$ & $\mathrm{c}$ & $c^{\prime}$ & & & \\
\hline \multicolumn{9}{|c|}{ DV = Willingness to pay for an eco-friendly version of a dishwashing soap $(\mathrm{N}=233)^{c}$} \\
\hline \multirow[t]{2}{*}{ INS } & $\mathrm{b}$ & 0.45 & 0.16 & 0.05 & -0.02 & 0.07 & -0.01 & 0.07 \\
\hline & $\boldsymbol{p}$ & $<0.001$ & $<0.001$ & 0.17 & 0.53 & $<0.01$ & $>0.10$ & $<0.001$ \\
\hline \multirow[t]{2}{*}{ CNS } & b & 0.65 & 0.13 & 0.15 & 0.07 & 0.08 & 0.02 & 0.07 \\
\hline & $\boldsymbol{p}$ & $<0.001$ & 0.003 & 0.005 & 0.25 & $<0.01$ & $>0.10$ & $<0.001$ \\
\hline \multirow[t]{2}{*}{ LCN } & $\boldsymbol{b}$ & 0.64 & 0.12 & 0.13 & 0.05 & 0.08 & 0.03 & 0.07 \\
\hline & $p$ & $<0.001$ & 0.01 & 0.002 & 0.34 & $<0.01$ & $>0.10$ & $<0.001$ \\
\hline \multicolumn{9}{|c|}{ DV = Hypothetical choice of high performance vs. eco-friendly phone } \\
\hline \multirow[t]{2}{*}{ INS } & b & 0.47 & 0.97 & 0.38 & 0.03 & 0.45 & 0.02 & $\mathrm{n} / \mathrm{a}$ \\
\hline & $\boldsymbol{p}$ & $<0.001$ & $<0.001$ & 0.001 & 0.83 & $<0.01$ & $>0.10$ & $\mathrm{n} / \mathrm{a}$ \\
\hline \multirow[t]{2}{*}{ CNS } & b & 0.67 & 0.76 & 1.12 & 0.75 & 0.51 & 0.27 & $\mathrm{n} / \mathrm{a}$ \\
\hline & $\boldsymbol{p}$ & $<0.001$ & $<0.001$ & $<0.001$ & 0.001 & $<0.01$ & $<0.01$ & $\mathrm{n} / \mathrm{a}$ \\
\hline \multirow[t]{2}{*}{ LCN } & $\boldsymbol{b}$ & 0.64 & 0.79 & 0.75 & 0.35 & 0.51 & 0.20 & $\mathrm{n} / \mathrm{a}$ \\
\hline & $\boldsymbol{p}$ & $<0.001$ & $<0.001$ & $<0.001$ & 0.05 & $<0.01$ & $<0.10$ & $\mathrm{n} / \mathrm{a}$ \\
\hline \multicolumn{9}{|c|}{ DV = Hypothetical choice of high performance vs. eco-friendly shoes } \\
\hline \multirow[t]{2}{*}{ INS } & b & 0.47 & 0.45 & 0.17 & -0.03 & 0.21 & -0.02 & $\mathrm{n} / \mathrm{a}$ \\
\hline & $\boldsymbol{p}$ & $<0.001$ & 0.002 & 0.09 & 0.83 & $<0.01$ & $>0.10$ & $\mathrm{n} / \mathrm{a}$ \\
\hline \multirow[t]{2}{*}{ CNS } & b & 0.67 & 0.37 & 0.41 & 0.17 & 0.25 & 0.06 & $\mathrm{n} / \mathrm{a}$ \\
\hline & $\boldsymbol{p}$ & $<0.001$ & 0.007 & 0.01 & 0.36 & $<0.01$ & $>0.10$ & $\mathrm{n} / \mathrm{a}$ \\
\hline \multirow[t]{2}{*}{ LCN } & b & 0.64 & 0.47 & 0.22 & -0.07 & 0.30 & -0.04 & $\mathrm{n} / \mathrm{a}$ \\
\hline & $\boldsymbol{p}$ & $<0.001$ & 0.002 & 0.07 & 0.66 & $<0.01$ & $>0.10$ & $\mathrm{n} / \mathrm{a}$ \\
\hline
\end{tabular}

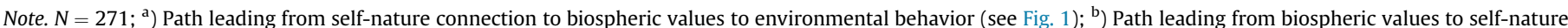

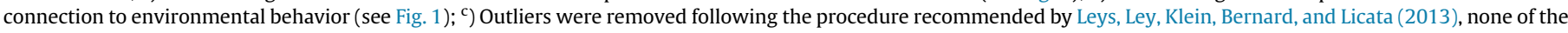

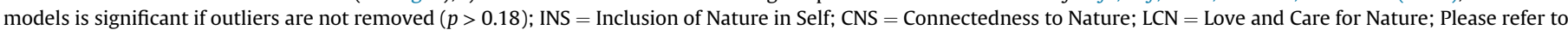
Fig. 2 for an explanation of the model's paths. 
Table A.2b

Mediation models in Study 3 based on hypothetical choices (based on the single-item biospheric values measure from Study 1).

\begin{tabular}{|c|c|c|c|c|c|c|c|c|}
\hline \multirow{2}{*}{ Measure of self-nature connection } & \multirow{2}{*}{ Coeff } & \multicolumn{4}{|l|}{ Paths } & \multirow{2}{*}{ Indirect effect ${ }^{\mathrm{a}}$} & \multirow{2}{*}{ Reversed indirect ${ }^{\mathrm{b}}$} & \multirow{2}{*}{$R^{2}$} \\
\hline & & $\bar{a}$ & ( & & $\mathrm{c}^{\prime}$ & & & \\
\hline \multicolumn{9}{|c|}{ DV = Willingness to pay for an eco-friendly version of a dishwashing soap $(N=233)^{c}$} \\
\hline \multirow[t]{2}{*}{ INS } & b & 10.60 & 0.01 & 0.05 & -0.03 & 0.08 & -0.00 & 0.07 \\
\hline & $\boldsymbol{p}$ & $<0.001$ & $<0.001$ & 0.18 & 0.44 & $<0.01$ & $>0.10$ & $<0.001$ \\
\hline \multirow[t]{2}{*}{ CNS } & b & 16.23 & 0.01 & 0.15 & 0.05 & 0.10 & 0.00 & 0.07 \\
\hline & $\boldsymbol{p}$ & $<0.001$ & 0.002 & 0.005 & 0.38 & $<0.01$ & $>0.10$ & $<0.001$ \\
\hline \multirow[t]{2}{*}{ LCN } & $\boldsymbol{b}$ & 14.93 & 0.01 & 0.13 & 0.04 & 0.09 & 0.00 & 0.07 \\
\hline & $p$ & $<0.001$ & 0.004 & 0.002 & 0.43 & $<0.01$ & $>0.10$ & $<0.001$ \\
\hline \multicolumn{9}{|c|}{ DV = Hypothetical choice of high performance vs. eco-friendly phone } \\
\hline \multirow[t]{2}{*}{ INS } & $\boldsymbol{b}$ & 10.39 & 0.04 & 0.38 & 0.08 & 0.37 & 0.00 & $\mathrm{n} / \mathrm{a}$ \\
\hline & $\boldsymbol{p}$ & $<0.001$ & $<0.001$ & 0.001 & 0.56 & $<0.01$ & $>0.10$ & $\mathrm{n} / \mathrm{a}$ \\
\hline \multirow[t]{2}{*}{ CNS } & b & 16.56 & 0.03 & 1.12 & 0.75 & 0.43 & 0.01 & $\mathrm{n} / \mathrm{a}$ \\
\hline & $\boldsymbol{p}$ & $<0.001$ & $<0.001$ & $<0.001$ & 0.002 & $<0.01$ & $<0.01$ & $\mathrm{n} / \mathrm{a}$ \\
\hline \multirow[t]{2}{*}{ LCN } & b & 14.46 & 0.03 & 0.75 & 0.39 & 0.41 & 0.01 & $\mathrm{n} / \mathrm{a}$ \\
\hline & $\boldsymbol{p}$ & $<0.001$ & $<0.001$ & $<0.001$ & 0.03 & $<0.01$ & $<0.05$ & $\mathrm{n} / \mathrm{a}$ \\
\hline \multicolumn{9}{|c|}{ DV = Hypothetical choice of high performance vs. eco-friendly shoes } \\
\hline \multirow[t]{2}{*}{ INS } & b & 10.39 & 0.01 & 0.17 & 0.04 & 0.14 & 0.00 & $\mathrm{n} / \mathrm{a}$ \\
\hline & $\boldsymbol{p}$ & $<0.001$ & 0.02 & 0.09 & 0.76 & $<0.05$ & $>0.10$ & $\mathrm{n} / \mathrm{a}$ \\
\hline \multirow[t]{2}{*}{ CNS } & $\boldsymbol{b}$ & 16.56 & 0.01 & 0.41 & 0.23 & 0.18 & 0.00 & $\mathrm{n} / \mathrm{a}$ \\
\hline & $\boldsymbol{p}$ & $<0.001$ & 0.06 & 0.01 & 0.22 & $<0.10$ & $>0.10$ & $\mathrm{n} / \mathrm{a}$ \\
\hline \multirow[t]{2}{*}{ LCN } & $\boldsymbol{b}$ & 14.46 & 0.01 & 0.22 & 0.02 & 0.20 & 0.00 & $\mathrm{n} / \mathrm{a}$ \\
\hline & $\boldsymbol{p}$ & $<0.001$ & 0.02 & 0.07 & 0.88 & $<0.05$ & $>0.10$ & $\mathrm{n} / \mathrm{a}$ \\
\hline
\end{tabular}

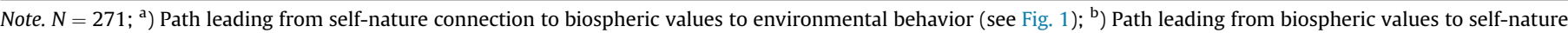

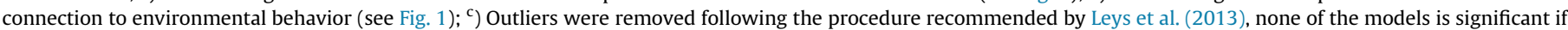

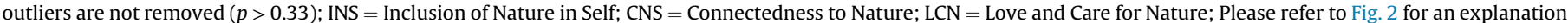
of the model's paths.

\section{References}

Angrist, J. D., \& Pischke, J.-S. (2009). Mostly harmless econometrics: An empiricist's companion. Princeton, NJ: Princeton University Press.

Antonakis, J., Bendahan, S., Jacquart, P., \& Lalive, R. (2010). On making causal claims: A review and recommendations. Leadership Quarterly, 21, 1086-1120.

Bolderdijk, J. W., Gorsira, M., Keizer, K., \& Steg, L. (2013). Values determine the (in) effectiveness of informational interventions in promoting pro-environmental behavior. PLoS One, 8(12).

Boomsma, C., \& Steg, L. (2014). The effect of information and values on acceptability of reduced street lighting. Journal of Environmental Psychology, 39, 22-31.

Brown, T. A. (2006). Confirmatory factor analysis for applied research. New York, NY: Guilford Press.

Clayton, S. (2012a). Environment and identity. In S. Clayton (Ed.), Handbook of environmental and conservation psychology (pp. 164-180). New York, NY: Oxford University Press.

Clayton, S. (2012b). Handbook of environmental and conservation psychology. New York, NY: Oxford University Press.

Clayton, S., \& Opotow, S. (2003). Identity and the natural environment: The psychological significance of nature. Cambridge, MA: MIT Press.

Collado, S., Staats, H., \& Corraliza, J. A. (2013). Experiencing nature in children's summer camps: Affective, cognitive and behavioural consequences. Journal of Environmental Psychology, 33, 37-44.

Cornelissen, G., Pandelaere, M., Warlop, L., \& Dewitte, S. (2008). Positive cueing: Promoting sustainable consumer behavior by cueing common environmenta behaviors as environmental. International Journal of Research in Marketing, 25, 46-55.

Crompton, T., \& Kasser, T. (2009). Meeting environmental challenges: The role of human identity. Surrey, UK: WWF-UK.

Crompton, T., \& Kasser, T. (2010). Human identity: A missing link in environmental campaigning. Environment: Science \& Policy for Sustainable Development, 52, $23-33$.

Diamantopoulos, A., Sarstedt, M., Fuchs, C., Wilczynski, P., \& Kaiser, S. (2012) Guidelines for choosing between multi-item and single-item scales for construct measurement: A predictive validity perspective. Journal of the Academy of Marketing Science, 40, 434-449.

Dietz, T., Gardner, G. T., Gilligan, J., Stern, P. C., \& Vandenbergh, M. P. (2009) Household actions can provide a behavioral wedge to rapidly reduce US carbon emissions. Proceedings of the National Academy of Sciences, 106, 18452-18456.

Dutcher, D. D., Finley, J. C., Luloff, A. E., \& Johnson, J. B. (2007). Connectivity with nature as a measure of environmental values. Environment and Behavior, 39 $474-493$.

Farrell, A. M. (2010). Insufficient discriminant validity: A comment on Bove, Pervan, Beatty, and Shiu (2009). Journal of Business Research, 63, 324-327.

Fornell, C., \& Larcker, D. F. (1981). Evaluating structural equation models with unobservable variables and measurement error. Journal of Marketing Research, 18 39-50.

Frantz, C. M., \& Mayer, F. S. (2014). The importance of connection to nature in assessing environmental education programs. Studies in Educational Evaluation, 41, 85-89.

Furchheim, P. (2016). Grüner Materialismus - Eine Überprüfung der Vereinbarkeit von Materialismus und grünem Konsum [Green materialism - A test of the compatibility of materialism and green consumption]. Wiesbaden, Germany: Gabler Verlag.

Gifford, R., \& Nilsson, A. (2014). Personal and social factors that influence proenvironmental concern and behaviour: A review. International Journal of Psychology, 49, 141-157.

Haws, K. L., Winterich, K. P., \& Naylor, R. W. (2014). Seeing the world through GREEN-tinted glasses: Green consumption values and responses to environmentally friendly products. Journal of Consumer Psychology, 24, 336-354.

Heine, S. J., \& Norenzayan, A. (2006). Toward a psychological science for a cultural species. Perspectives on Psychological Science, 1, 251-269.

Hinds, J., \& Sparks, P. (2008). Engaging with the natural environment: The role of affective connection and identity. Journal of Environmental Psychology, 28, $109-120$.

Hitlin, S. (2003). Values as the core of personal identity: Drawing links between two theories of self. Social Psychology Ouarterly, 66, 118-137.

Hoffarth, M. R., \& Hodson, G. (2016). Green on the outside, red on the Inside: Perceived environmentalist threat as a factor explaining political polarization of climate change. Journal of Environmental Psychology, 45, 40-49.

Kasser, T., Ryan, R. M., Couchman, C. E., \& Sheldon, K. M. (2004). Materialistic values: Their causes and consequences. In T. Kasser, \& A. D. Kanner (Eds.), Psychology and consumer culture: The struggle for a good life in a materialistic world (pp. 11-28). Washington, DC: American Psychological Association.

Leopold, A. (1949). A sand county almanac: With essays on conservation from Round River. New York: Oxford University Press.

Levin, S., \& Sidanius, J. (1999). Social dominance and social identity in the United States and Israel: Ingroup favoritism or outgroup derogation? Political Psychology, 20, 99-126.

Leys, C., Ley, C., Klein, O., Bernard, P., \& Licata, L. (2013). Detecting outliers: Do not use standard deviation around the mean, use absolute deviation around the median. Journal of Experimental Social Psychology, 49, 764-766.

Luchs, M. G., Naylor, R. W., Irwin, J. R., \& Raghunathan, R. (2010). The sustainability liability: Potential negative effects of ethicality on product preference. Journal of Marketing, 74(5), 18-31.

Martin, C., \& Czellar, S. (2016). The extended inclusion of nature in self scale. Journal of Environmental Psychology, 47, 181-194.

Mayer, F. S., \& Frantz, C. M. (2004). The connectedness to nature scale: A measure of individuals' feeling in community with nature. Journal of Environmental Psychology, 24, 503-515.

Mayer, F. S., Frantz, C. M., Bruehlman-Senecal, E., \& Dolliver, K. (2009). Why is nature beneficial? The role of connectedness to nature. Environment and Behavior, 41, 607-643.

National Geographic. (2014). Greendex: Consumer choice and the environment - a worldwide tracking survey. Retrieved July 4, 2015, from. Retrieved July 4, 2015, from http://environment.nationalgeographic.com/environment/greendex/.

Nisbet, E. K., Zelenski, J. M., \& Murphy, S. A. (2009). The nature relatedness scale: 
Linking individuals' connection with nature to environmental concern and behavior. Environment and Behavior, 41, 715-740.

Osbaldiston, R., \& Schott, J. P. (2012). Environmental sustainability and behavioral science: Meta-analysis of proenvironmental behavior experiments. Environment and Behavior, 44, 257-299.

Perkins, H. E. (2010). Measuring love and care for nature. Journal of Environmental Psychology, 30, 455-463.

Perrin, J. L., \& Benassi, V. A. (2009). The connectedness to nature scale: A measure of emotional connection to nature? Journal of Environmental Psychology, 29, 434-440.

Podsakoff, P. M., MacKenzie, S. B., Lee, J. Y., \& Podsakoff, N. P. (2003). Common method biases in behavioral research: A critical review of the literature and recommended remedies. Journal of Applied Psychology, 88, 879-903.

Preacher, K. J., \& Hayes, A. F. (2008). Asymptotic and resampling strategies for assessing and comparing indirect effects in multiple mediator models. Behavior Research Methods, 40, 879-891.

Roszak, T. (1995). Where psyche meets gaia. In T. Roszak, M. E. Gomes, \& A. D. Kanner (Eds.), Ecopsychology: Restoring the earth, healing the mind (pp. 1-9). San Francisco, CA: Sierra Club Books.

Salzberger, T. (2007, December). Single-item measures - Time for a revival. Paper presented at the Australia \& New Zealand Marketing Academy Conference, Dunedin, NZ.

Schultz, P. W. (2001). The structure of environmental concern: Concern for self, other people, and the biosphere. Journal of Environmental Psychology, 21, 327-339.

Schultz, P. W. (2002). Inclusion with nature: The psychology of human-nature relations. In P. Schmuck, \& P. W. Schultz (Eds.), Psychology of sustainable development (pp. 61-78). Dordrecht, Netherlands: Kluwer Academic Publishers.

Schultz, P. W., \& Kaiser, F. G. (2012). Promoting proenvironmental behavior. In S. Clayton (Ed.), Handbook of environmental and conservation psychology (pp. 556-580). New York, NY: Oxford University Press.

Schwartz, S. H. (2007). Value orientations: Measurement, antecedents and consequences across nations. In R. Jowell, C. Roberts, R. Fitzgerald, \& G. Eva (Eds.), Measuring attitudes cross-nationally - lessons from the European social survey (pp. 169-203). London, UK: Sage.

Schwartz, S. H. (2012). An overview of the Schwartz theory of basic values. Online Readings in Psychology and Culture, 2, 1-20.

Soyez, K. (2012). How national cultural values affect pro-environmental consumer behavior. International Marketing Review, 29, 623-646.

Sparks, P., Hinds, J., Curnock, S., \& Pavey, L. (2014). Connectedness and its consequences: A study of relationships with the natural environment. Journal of
Applied Social Psychology, 44, 166-174

Staiger, D., \& Stock, J. H. (1997). Instrumental variables regression with weak instruments. Econometrica, 65, 557-586.

Steenkamp, J.-B. E. M., \& de Jong, M. G. (2010). A global investigation into the constellation of consumer attitudes toward global and local products. Journal of Marketing, 74(6), 18-40.

Steg, L., Bolderdijk, J. W., Keizer, K., \& Perlaviciute, G. (2014). An integrated framework for encouraging pro-environmental behaviour: The role of values, situational factors and goals. Journal of Environmental Psychology, 38, 104-115.

Steg, L., \& de Groot, J. I. M. (2012). Environmental values. In S. D. Clayton (Ed.), The Oxford handbook of environmental and conservation psychology (pp. 81-92). New York, NY: Oxford University Press.

Steg, L., de Groot, J. I. M., Dreijerink, L., Abrahamse, W., \& Siero, F. (2011). General antecedents of personal norms, policy acceptability, and intentions: The role of values, worldviews, and environmental concern. Society \& Natural Resources 24(4), 349-367.

Stern, P. C., \& Dietz, T. (1994). The value basis of environmental concern. Journal of Social Issues, 50(3), 65-84.

Stern, P. C., Dietz, T., \& Kalof, L. (1993). Value orientations, gender, and environmental concern. Environment and Behavior, 25, 322-348.

Tajfel, H., \& Turner, J. C. (1986). The social identity theory of intergroup behavior. In S. Worchel, \& W. G. Austin (Eds.), The psychology of intergroup relations (pp. 7-24). Chicago: Nelson-Hall.

Tam, K.-P. (2013a). Concepts and measures related to connection to nature: Similarities and differences. Journal of Environmental Psychology, 34, 64-78.

Tam, K.-P. (2013b). Dispositional empathy with nature. Journal of Environmental Psychology, 35, 92-104.

Tam, K.-P., Lee, S.-L., \& Chao, M. M. (2013). Saving Mr. Nature: Anthropomorphism enhances connectedness to and protectiveness toward nature. Journal of Experimental Social Psychology, 49, 514-521.

United Nations General Assembly. (2000). United Nations millennium declaration. Retrieved March 30, 2015, from http://www.refworld.org/docid/3b00f4ea3. html.

Van der Werff, E., Steg, L., \& Keizer, K. (2013). The value of environmental selfidentity: The relationship between biospheric values, environmental selfidentity and pro-environmental preferences, intentions and behaviour. Journa of Environmental Psychology, 34, 55-63.

Van der Werff, E., Steg, L., \& Keizer, K. E. (2014). I am what I am, by looking past the present: The influence of biospheric values and past behavior on environmenta self-identity. Environment and Behavior, 46, 626-657. 